$9-15-2012$

\title{
Effect of Time-Dependent Material Properties on the Mechanical Behavior of PFSA Membranes Subjected to Humidity Cycling
}

\author{
Narinder S. Khattra
}

University of Delaware

Anette M. Karlsson

Cleveland State University, a.karlsson@csuohio.edu

Michael H. Santare

University of Delaware

PeterWWhatsdhd additional works at: https://engagedscholarship.csuohio.edu/enme_facpub fre Fuel Cell Technologies

Part of the Mechanical Engineering Commons

Fidplin Bsslaxess to this work benefit you? Let us know!

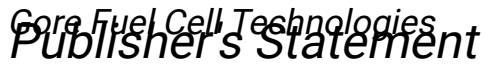

NOTICE: this is the author's version of a work that was accepted for publication in Journal of

Power Sources. Changes resulting from the publishing process, such as peer review, editing, corrections, structural formatting, and other quality control mechanisms may not be reflected in this document. Changes may have been made to this work since it was submitted for publication. A definitive version was subsequently published in Journal of Power Sources, 214, , (09-15-2012); 10.1016/j.jpowsour.2012.04.065

\section{Original Citation}

Khattra, N. S., Karlsson, A. M., Santare, M. H., 2012, "Effect of Time-Dependent Material Properties on the Mechanical Behavior of PFSA Membranes Subjected to Humidity Cycling," Journal of Power Sources, 214, pp. 365-376.

This Article is brought to you for free and open access by the Mechanical Engineering Department at EngagedScholarship@CSU. It has been accepted for inclusion in Mechanical Engineering Faculty Publications by an authorized administrator of EngagedScholarship@CSU. For more information, please contact library.es@csuohio.edu. 


\title{
Effect of time-dependent material properties on the mechanical behavior of PFSA membranes subjected to humidity cycling
}

\author{
Narinder S. Khattra ${ }^{a}$, Anette M. Karlsson ${ }^{\mathrm{a}, *}$, Michael H. Santare ${ }^{\mathrm{a}}$, Peter Walsh ${ }^{\mathrm{b}}$, F. Colin Busby ${ }^{\mathrm{b}}$ \\ a Department of Mechanical Engineering, 126 Spencer Laboratory, University of Delaware, Newark, DE 19716, USA \\ ${ }^{\mathrm{b}}$ Gore Fuel Cell Technologies, Elkton, MD 21922, USA
}

\section{Introduction}

Fuel cells represent a clean alternative to current technologies utilizing hydrocarbon fuel resources. However, key challenges to wide-spread commercialization of fuel cell technology include the high cost of materials and the relatively low durability [1]. The U.S. Department of Energy (DoE) has set a durability target of $5000 \mathrm{~h}$ of operation for PEM fuel cells [2] (corresponding to 150,000 miles equivalent in a vehicle). Since the membrane life can be a limiting factor in PEM fuel cell durability, this work focuses on the durability of the PFSA membranes commonly used in polymer electrolyte membrane (PEM) fuel cells.

During operation, heat and water are generated due to the electrochemical reaction associated with power generation. When

\footnotetext{
* Corresponding author. Tel.: +1 302831 2423; fax: +1 3028313619 . E-mail address: karlsson@udel.edu (A.M. Karlsson).
}

the power requirements change during use, the fuel cell structure is subjected to fluctuations in temperature and humidity. As a consequence, the structure is subjected to hygro-thermal cyclic loading, causing stresses in the membrane, which affect the mechanical durability.

Chemical and mechanical degradation mechanisms are coupled in actual fuel cell operation. Therefore, a full understanding of the durability of PEM fuel cell membranes must include both the chemical and mechanical factors that contribute to material degradation as functions of time, and their interaction with hygrothermal load conditions experienced during the operating and nonoperating periods [1]. However, this work will focus on the mechanical aspects of degradation, since this degradation has not been studied as comprehensively as chemical degradation.

Mechanical damage is typically manifested as pinhole formation or cracking and can be accelerated by RH cycling as well as low humidification of the feed stream $[3,4]$. Once these flaws are 
formed, gasses may pass through the membrane compromising the fuel cell function $[3,4]$. In general, the mechanical damage is caused by the cyclic hygro-thermal loading in the cell [5]. In an unconstrained state, the membrane experiences swelling and shrinkage during water sorption, desorption and thermal cycling. However, the membrane electrode assembly (MEA) is constrained from deformation by the stiffer gas diffusion media and bipolar plates in a fuel cell. These constraints cause the membrane to develop compressive stress at higher levels of water uptake and high temperature during operation [6-8]. If these compressive stresses are high enough to cause inelastic deformation, tensile residual stresses may develop upon dehydration and cooling of the membrane [6,9].

There are several cyclical, hygro-thermal accelerated aging tests, which are used to assess the mechanical durability of membranes in the absence of electrochemical activity $[2,10]$. These test protocols provide a basis for comparison of the purely mechanical behavior of different membrane material compositions and designs. In this work, we will focus on the stress response of PFSAbased membranes under these standardized RH cycling conditions. In order to determine how the stresses evolve during loading, the mechanical properties of the PFSA membrane must be established.

In our previous work, time-independent linear-elastic-plastic models were used to characterize the long-term membrane behavior [6,9]. However, our recent experiments [11] have shown significant time dependence that may have a significant effect on the stresses in the membrane during fuel cell loading. Recent work has also been published on time-dependent models for PFSA membranes [12-14]. Most of the models assume that the response is viscoelastic, therefore inelastic effects have been not been studied thoroughly. Patankar et al. [15] investigated the viscoelastic properties of Gore-Select ${ }^{\circledR} 57$ PFSA membrane using dynamic mechanical analysis (DMA). They used time-temperature superposition to create a hygro-thermal master curve. Solasi et al. [12] used a viscoplastic constitutive model for investigating the behavior of a dispersion cast PFSA membrane. They measured the uniaxial stress response of the membrane for a few temperature and hydration levels in the fuel cell operating range. The model did not account for strain rate dependence of the instantaneous elastic modulus, a phenomenon observed in their experiments and in our test data [11]. Silberstein et al. [13] used a micromechanically motivated constitutive model to capture the monotonic and cyclic stress response of a dispersion cast membrane. The measurements were conducted using DMA and therefore do not measure the longterm stress-relaxation behavior. Yoon et al. [14] used a phenomenological constitutive model for ionomer membranes based on micromechanisms of polymer deformation. The long-term stressrelaxation behavior was not considered while validating the model. Yan et al. [16] characterized the material response of the PFSA membrane using a non-linear viscoelastic model based on Schapery's single integral method. Lai et al. [17] used a linear viscoelastic theory with time, temperature and hydration dependent material properties to simulate the stresses developed in the membrane under RH cycling. They predicted residual tensile stresses in the membrane to be as high as $10.6 \mathrm{MPa}$, which is near or higher than the proportional limit stress at various conditions [11] suggesting the need for a viscoplastic approach to modeling of the membrane material. Silberstein et al. [18] used elastic-viscoplastic properties for the PFSA membrane and investigated the membrane response via experiments under partially constrained swelling in a bimaterial strip and report plastic deformation in the membrane. Their $\mathrm{RH}$ cycle simulations predicted maximum in-plane stress of around $12 \mathrm{MPa}$. Li et al. [19] also used a bimaterial strip to measure hygral stresses in the membrane and attribute the tensile stress in the membrane upon dehydration to the viscoelastic nature of the membrane instead of plastic deformation.
From the above discussed studies, it appears that there is no consensus regarding plastic deformation in the membrane. However, on the basis of our experimental data [11] and numerical evaluation of strain in the membrane during fuel cell RH cycling (around 15\%), we believe that there is inelastic deformation in the membrane and it can play a critical role in the failure mechanisms of the membrane. Therefore, a viscoelastic-plastic constitutive behavior for the membrane will be investigated in the current work.

In a companion study [11], we describe the set of uniaxial tension and stress-relaxation tests conducted at various load rates and hold strains to determine the viscoelastic-plastic material parameters over a range of environmental conditions. In the current work, we use these properties to develop a modified two-layer viscoelasticplastic constitutive model for the membrane. Section 2 describes the two-layer viscoelastic-plastic model used and in section 3, the experimentally determined mechanical properties [11] are presented and compared to the constitutive model predictions. Simulations of the uniaxial tensile and stress-relaxation experiments are discussed in Appendix A and Appendix B respectively. In section 4 we incorporate the two-layer model into a finite element simulation of a volume element in a typical fuel cell to explore the effects of these properties on the stress evolution. Finally, the finite element simulation results for a membrane undergoing two standardized $\mathrm{RH}$ cycle tests are presented and discussed in section 5 . The in-plane stresses in the membrane, which have been shown to be the critical stresses [7,8], are reported for a selected range of temperature and humidity cycle time parameters.

\section{Constitutive model of the membrane}

In this section, we present a constitutive model capable of capturing the hygro-thermo-mechanical time-dependent response of the membrane. The model extends the linear-elastic [9], the linear-elastic, perfectly-plastic [6] and the linear-elastic-plastic with isotropic hardening [7] models we have previously developed to simulate the mechanical response of the membrane. The constitutive material parameters are all functions of relative humidity $(\mathrm{RH})$ and temperature as determined in the experiments [11].

We assume that the total strain tensor, $\varepsilon_{i j}$, is given as the sum

$\varepsilon_{i j}=\underline{\varepsilon}_{i j}^{\mathrm{H}}+\varepsilon_{i j}^{\mathrm{T}}+\varepsilon_{i j}^{\mathrm{M}} ; \quad(i=\geq 1,2,3)$,

where $\varepsilon_{i j}^{\mathrm{H}}, \varepsilon_{i j}^{\mathrm{T}}$ and $\varepsilon_{i j}^{\mathrm{M}}$ are the swelling, thermal and mechanical strain contributions, respectively. Each of these strains is discussed below.

\subsection{Swelling strains}

Assuming isotropic swelling, the swelling strains in the membrane, caused by water uptake, are calculated using the empirical relationship from Kusoglu et al. [20],

$\varepsilon_{\text {iso }}^{\mathrm{H}}=\frac{1}{3} \quad \frac{\theta}{\theta_{\mathrm{o}}} \ln \frac{1}{\phi_{\mathrm{P}}}$,

where $\theta$ and $\theta_{0}$ are the current and reference temperature (expressed in degrees $\mathrm{K}$ ), respectively. $\phi_{\mathrm{P}}$ is the polymer volume fraction given by

$\phi_{\mathrm{P}}=\frac{\mathrm{EW} / \rho_{\mathrm{P}}}{18 \lambda+\mathrm{EW} / \rho_{\mathrm{P}}}$,

where $\lambda$ is the number of water molecules attached to each sulphonic acid group, EW is the equivalent weight of the ionomer and $\rho_{\mathrm{P}}$ is the density of the dry ionomer material. 


\subsection{Thermal strains}

Assuming isotropic thermal expansion, the thermal strains in the membrane caused by a change in temperature $\left(\theta-\theta_{0}\right)$ are given by

$\varepsilon_{i j}^{\mathrm{T}}=\geq \alpha\left(\theta-\theta_{0}\right) \delta_{i j}$,

where $\alpha$ is the linear coefficient of thermal expansion and $\delta_{i j}$ is the Kronecker delta given by

$\delta_{i j}=\geq\left\{\begin{array}{ll}1 & ; i=>j \\ 0 & ; i \neq j\end{array}\right.$.

\subsection{Mechanical strains}

In this study, the mechanical strains, $\varepsilon_{i j}^{\mathrm{M}}$, are defined in the context of the viscoelastic-plastic model [21,22] shown in Fig. 1. This model consists of two "layers", one corresponding to the timeindependent elastic-plastic response and the other corresponding to the time-dependent elastic-viscous response. The two-layer model was chosen due to its relative simplicity, containing 6 empirically determined material parameters. By definition, the total mechanical strain, $\varepsilon_{i j}^{\mathrm{M}}$, is equal in both layers

$\varepsilon_{i j}^{\mathrm{M}}=\underline{x}_{i j}^{\mathrm{EP}}=\underline{\varepsilon}_{i j}^{\mathrm{EV}}$,

where the superscripts EP and EV refer to elastic-plastic and elastic-viscous layers of the model, respectively. In the elastic-plastic layer, the total strain is the sum of the linear-elastic strain in the spring element $\left(\varepsilon_{i j}^{\mathrm{EP}}\right)_{\mathrm{el}}$ and the rate-independent plastic strain in the slider element $\left(\varepsilon_{i j}^{\mathrm{EP}}\right)_{\mathrm{pl}}$

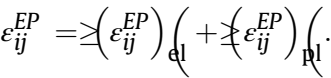

Extrapolating the spring concept in the elastic-plastic layer to represent a generalized three-dimensional isotropic Hooke's law response, the elastic strain can be written as a function of the stress in the elastic-plastic layer, $\sigma_{i j}^{\mathrm{EP}}$

$\left(\varepsilon_{i j}^{\mathrm{EP}}\right) \oint_{\mathrm{l}}=\geq \frac{1+\nu}{K_{\mathrm{P}}} \sigma_{i j}^{\mathrm{EP}}-\frac{\nu}{K_{\mathrm{P}}} \delta_{i j} \sigma_{k k}^{\mathrm{EP}}$,

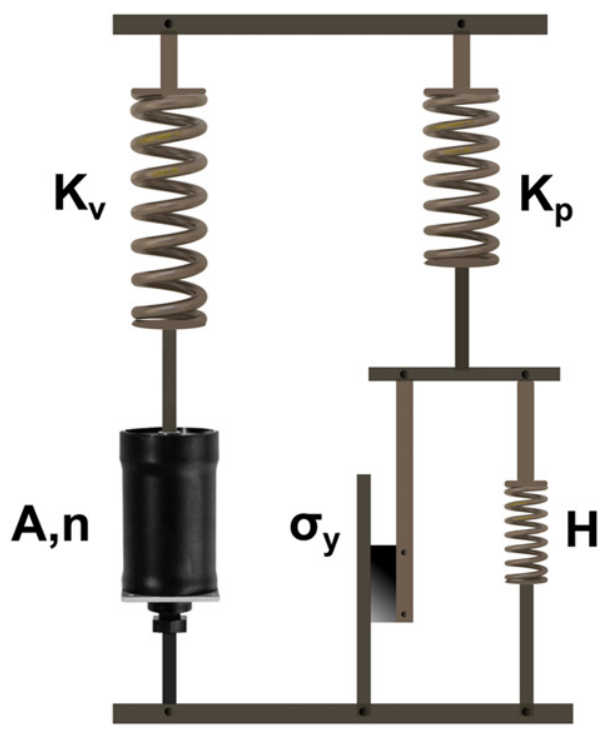

Fig. 1. One-dimensional idealization of the two-layer viscoelastic-plastic model $[21,22]$. where $\nu$ is Poisson's ratio and $K_{\mathrm{P}}$ is the stiffness of the elastic element in this layer.

Assuming isotropic strain hardening (represented by the spring, $H$, parallel to the slider element), the yield strength is a function of the plastic strain as well as being a function of the relative humidity, $\Re$, and temperature, $\theta$,

$\sigma_{\mathrm{y}}=\sigma_{\mathrm{y}}\left(\left(\bar{\varepsilon}_{i j}^{\mathrm{EP}}\right)_{\mathrm{Rl}}, \Re, \theta\right)$.

In this expression, $\left(\bar{\varepsilon}_{i j}^{\mathrm{EP}}\right)_{\mathrm{pl}}$ is the equivalent plastic strain given by

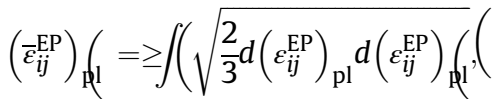

where $d\left(\varepsilon_{i j}^{E P}\right)_{\mathrm{pl}}$ are the increments of plastic strain tensor.

Using von Mises' yield criterion [23], the rate-independent plastic flow is given by

$f\left(\sigma_{i j}\right)\left(=\geq \sqrt{\frac{3}{2} S_{i j} S_{i j}}\left(-\sigma_{\mathrm{y}}\right.\right.$,

where $\sigma_{\mathrm{y}}$ is the yield strength of the material and $S_{i j}$ are the deviatoric stress tensor components defined by

$S_{i j}=\underline{\sigma}_{i j}-\frac{1}{3} \sigma_{k k} \delta_{i j}$

Under von Mises' yield criterion, the material deforms elastically for $f\left(\sigma_{i j}\right)<0$ and yielding occurs when

$f\left(\sigma_{i j}, \bar{\varepsilon}_{i j}^{\mathrm{pl}}\right) \quad 0$.

The total strain in the elastic-viscous layer is the sum of linearelastic strain in the spring $K_{\mathrm{v}}$ and the viscous strain in the dashpot element given by

$\left.\varepsilon_{i j}^{\mathrm{EV}}=\geq\left(\varepsilon_{i j}^{\mathrm{EV}}\right) \oint_{\mathrm{l}}+\geq \varepsilon_{i j}^{\mathrm{EV}}\right)\left(_{\dot{\mathrm{i}}}\right.$,

where subscript el refers to the elastic portion and vi refers to the viscous portion of the strain. Again, assuming isotropic Hooke's law for the linear-elastic constitutive response of the spring in this layer, the generalized, three-dimensional elastic strain as a function of the stress, $\sigma_{i j}^{\mathrm{EV}}$, is given by

$\left(\varepsilon_{i j}^{\mathrm{EV}}\right)_{\varepsilon_{1}}=\geq \frac{1+\nu}{K_{\mathrm{V}}} \sigma_{i j}^{\mathrm{EV}}-\frac{\nu}{K_{\mathrm{V}}} \delta_{i j} \sigma_{k k}^{\mathrm{EV}}$.

For the dashpot element, the Norton-Hoff stress-strain rate law [24] is used, the generalized three-dimensional time-dependent form of which is written as

$\dot{\varepsilon}_{i j}^{\mathrm{vi}}=\underline{A}\left(\sigma_{i j}^{\mathrm{vi}}\right)^{n}$

where $A$ and $n$ are material parameters.

\section{Mechanical properties of the PFSA membrane}

The mechanical response of PFSA membrane depends on temperature, water content and loading rate [11]. In this section, the experimental data from the uniaxial tensile and stressrelaxation tests conducted on PFSA Nafion ${ }^{\circledR} 211^{1}$ membrane are fitted to the two-layer model introduced in the previous section using the equations presented in Appendix A and Appendix B.

\footnotetext{
${ }^{1}$ Nafion is a registered trademark of E.I. du Pont de Nemours, Inc. Co.
} 
The material parameters thus obtained (Fig. 2) were used in FE model simulations of the test specimens to compare the model predictions to test data. To do this, a plane stress ABAQUS [22] finite element model was developed with gauge length of $50 \mathrm{~mm}$ and width of $20 \mathrm{~mm}$, and meshed using CPS8R elements (plane stress, 8 -node biquadratic, reduced integration). Selected sample results are shown in Fig. 3. The figure shows that the constitutive model captures the initial elastic and non-linear behavior well. We assume that the onset of nonlinearity corresponds to the onset of inelastic behavior of the membrane. It also captures the variation in the initial stiffness and the overall increase in stress due to changing load rates fairly well. This capability is not present in the original two-layer model [21,22], but was accomplished in the present work by adding strain rate dependence to the spring element in the elastic-viscous layer of the viscoelastic-plastic model. The strain rate dependence was incorporated into the model by introducing a strain rate dependent function for the elastic-viscous stiffness element, $K_{\mathrm{v}}$ and using values for the stiffness determined from the tensile tests conducted at various load rates. In the finite element model, the strain rate dependence is handled via an ABAQUS user subroutine USDFLD [22] which assigns the instantaneous stiffness values to the material depending on the current strain rate in the model.

In Fig. 4, the model predictions of the stress-relaxation test are compared with the experimental data for selected conditions. The model captures the stress peak and the relaxation behavior for the observed time frame of about $1-1.5 \mathrm{~h}$. The trend suggests that relaxation continues beyond the test time although at a decreasing rate. Due to limitations of the testing equipment and practical considerations, relaxation beyond $1.5 \mathrm{~h}$ was not considered.

Thus, the FE simulations, using the relatively-simple, two-layer model with properties shown in Fig. 2, capture the experimentally measured [11] membrane behavior fairly well. In the next section we will incorporate these material properties into finite element simulations of a representative volume element of a fuel cell, subjected to humidity cycling.

\section{Numerical implementation}

In this section, the effect of time-dependent properties on the behavior of PFSA membranes in a fuel cell unit operating under $\mathrm{RH}$ cycling is investigated via numerical simulations. The simulations are based on finite element analyses using the commercial software

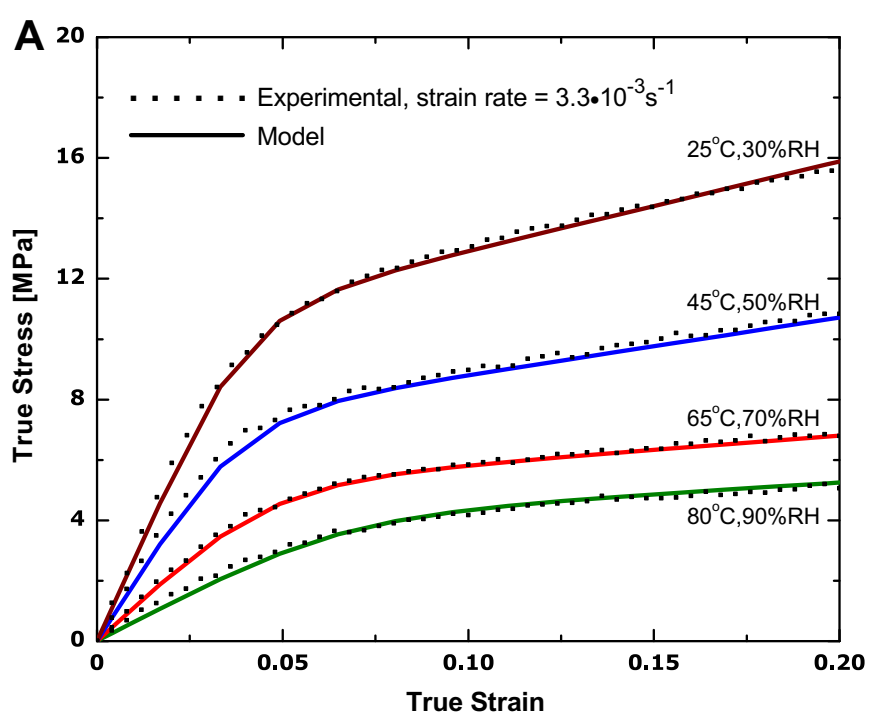

B

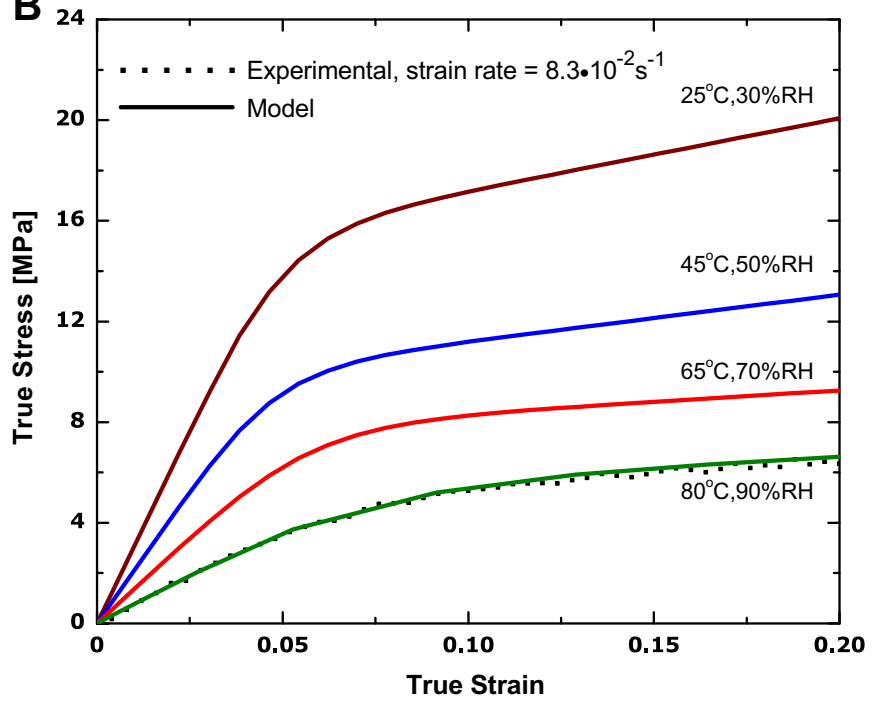

Fig. 3. $[A]$ True stress vs. true strain uniaxial tensile response of the PFSA membrane at various environmental conditions obtained experimentally [2] compared with the constitutive model predictions for strain rate $3 \cdot 3 \cdot 10^{-3} \mathrm{~s}^{-1}$ and [B] strain rate $8.3 \cdot 10^{-2} \mathrm{~s}^{-1}$.

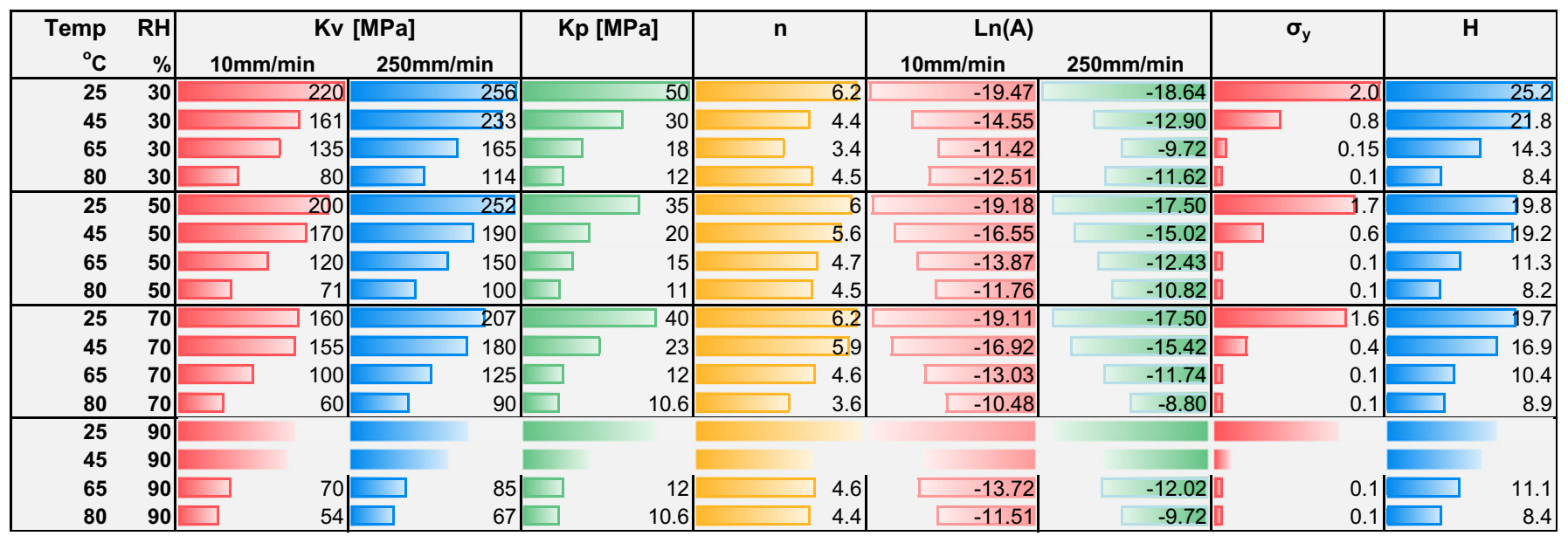

Fig. 2. Constitutive model parameters for the PFSA membrane. 


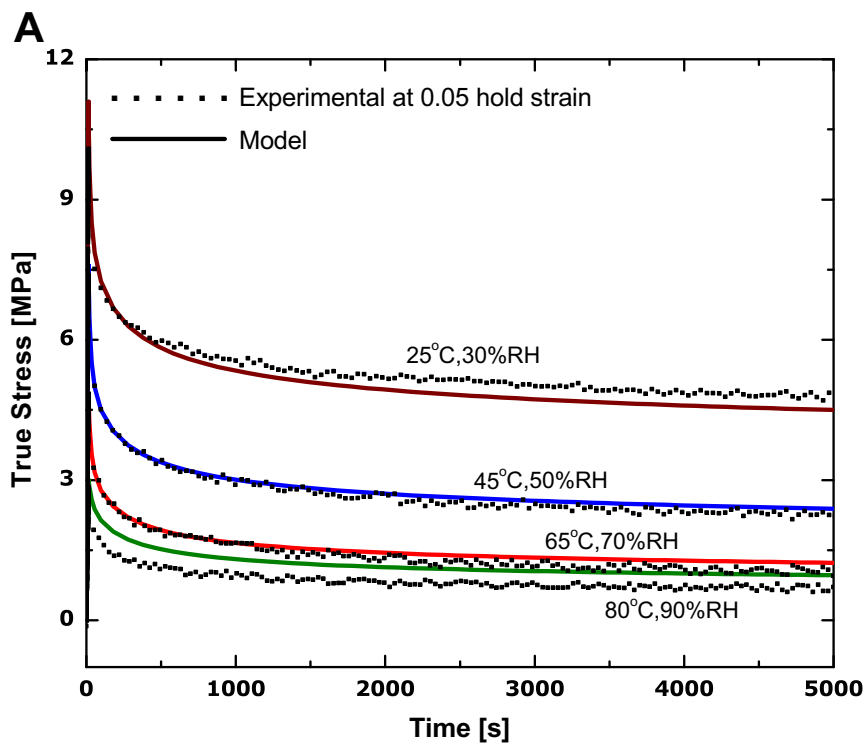

B

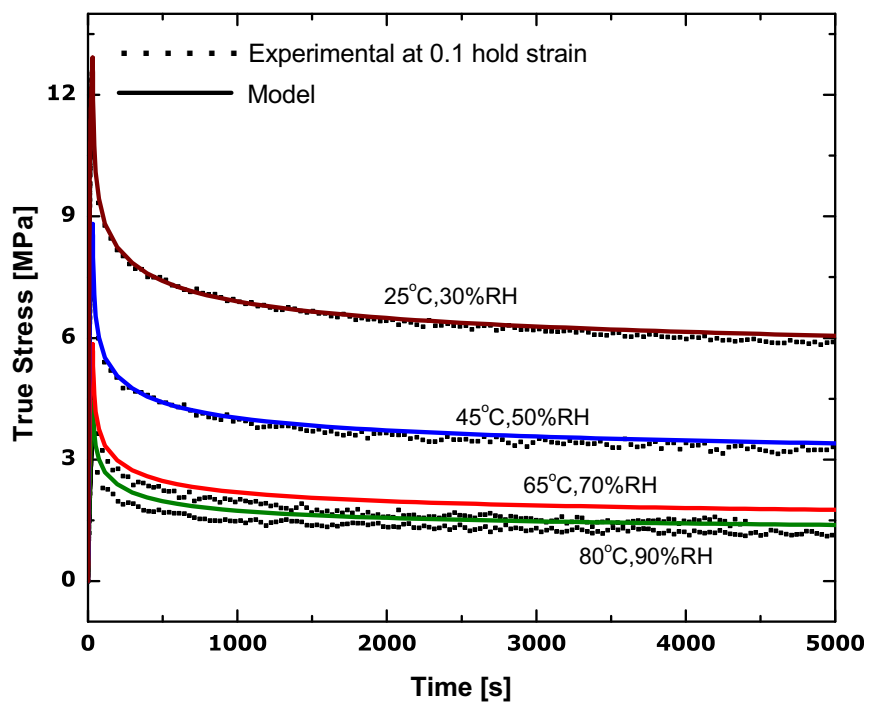

Fig. 4. [A] True stress vs. true strain stress-relaxation response of the PFSA membrane at various environmental conditions obtained experimentally [2] compared with the constitutive model predictions for hold strain 0.05 and [B] hold strain 0.1 .

ABAQUS 6.9 [22] with 8-noded biquadratic coupled temperaturedisplacement generalized plane strain elements (CPEG8T) and consists of 23,805 elements and 74,449 nodes with 10 elements along the thickness direction of the membrane (Fig. 5). Numerical convergence was verified using progressively finer meshes until no appreciable change was observed in the results.

\subsection{Geometry}

The geometry used for the numerical model is shown in Fig. 5. This model is adapted from our previous work $[6,7,9]$ where the time-independent response was studied. Generalized plane strain conditions are assumed, corresponding to a uniform strain in the out-of-plane $(z)$ direction. A typical fuel cell unit contains repetitive grooves and lands forming the gas channels in the bipolar plate. We constructed a model for a representative repeating element consisting of a half of a land and a half of a groove with the dimensions as shown in Fig. 5.
The right edge and bottom have symmetric boundary conditions imposed. To account for possible displacement in the in-plane (x) direction, a continuous boundary condition is applied under which all the nodes on left edge of the model can move in unison. A uniform pressure of $1 \mathrm{MPa}$ is applied from the top edge of bipolar plate to simulate a typical spring-loaded clamping pressure for a fuel cell.

\subsection{Properties}

The following material properties and behaviors are used for the various components in the finite element model:

1. Viscoelastic-plastic properties derived from the experiments are used for the PFSA membrane (section 3). The material properties and the sorption coefficient for the membrane are incorporated into the model as functions of water content and temperature. Poisson's ratio of 0.4 is assumed for the membrane [25].

2. The membrane is the only component that is assumed to swell due to water absorption.

3. Thermal expansion and swelling of the membrane are assumed isotropic for simplicity.

4. The bipolar plates are assumed to be linear-elastic and isotropic with elastic modulus and Poisson's ratio of $10 \mathrm{GPa}$ and 0.25 respectively. Thermal expansion is neglected.

5. The gas diffusion layer (GDL) is assumed to be linear-elastic and transversely isotropic with in-plane and the out-of-plane elastic moduli of $1500 \mathrm{MPa}$ and $9 \mathrm{MPa}$ respectively [26]. The coefficient of thermal expansion is $2.6 \times 10^{-9} \mathrm{~K}^{-1}$.

6 . The electrodes are assumed to have time-independent isotropic, elastic-plastic response with isotropic hardening.

\subsection{Load cases}

Standard test protocols have been established by the US Department of Energy (DoE) to assess the performance and durability of fuel cell components under cyclic loading $[2,27]$. The test protocol that targets mechanical durability is used for investigation of membrane performance in this work. This cycle is referred to as the "DoE cycle" in Fig. 6 and involves a constant temperature of $80^{\circ} \mathrm{C}$ while the humidity is cycled equally on both the anode and cathode sides, between dry and supersaturated conditions (corresponding to the dewpoint at $90{ }^{\circ} \mathrm{C}$ ). The maximum water volume fraction used in the analysis is $\Phi=0.32$. Using Eq. (3), this corresponds to a water content in the membrane $(\lambda)$ of around 14. The cell is held at the dry and wet state for $2 \mathrm{~min}$ each, and the transition is assumed to take place in a very short time ( $1 \mathrm{~s}$ in the simulation).

An alternative RH cycling test, developed by W. L. Gore, referred to as the "Gore cycle" in Fig. 6, is also investigated in this work [28]. This cycle involves similar conditions as the DoE cycle except that the cell is held in the wet state for 10 s and in the dry state for 50 s.

In both tests, humid and dry air are alternately forced into the flow channels, and therefore the actual water profile at the membrane is mediated by the diffusion through GDL, electrode and the membrane itself. The water volume fraction in the membrane and the other fuel cell components is modeled as an additional degree of freedom in addition to the nodal displacements in the finite element analysis. The water volume fraction for the membrane at the interface with the electrodes has a time-lag as shown in Fig. 7. Snapshots of the water content contours during hydration and dehydration are shown in Fig. 8. 


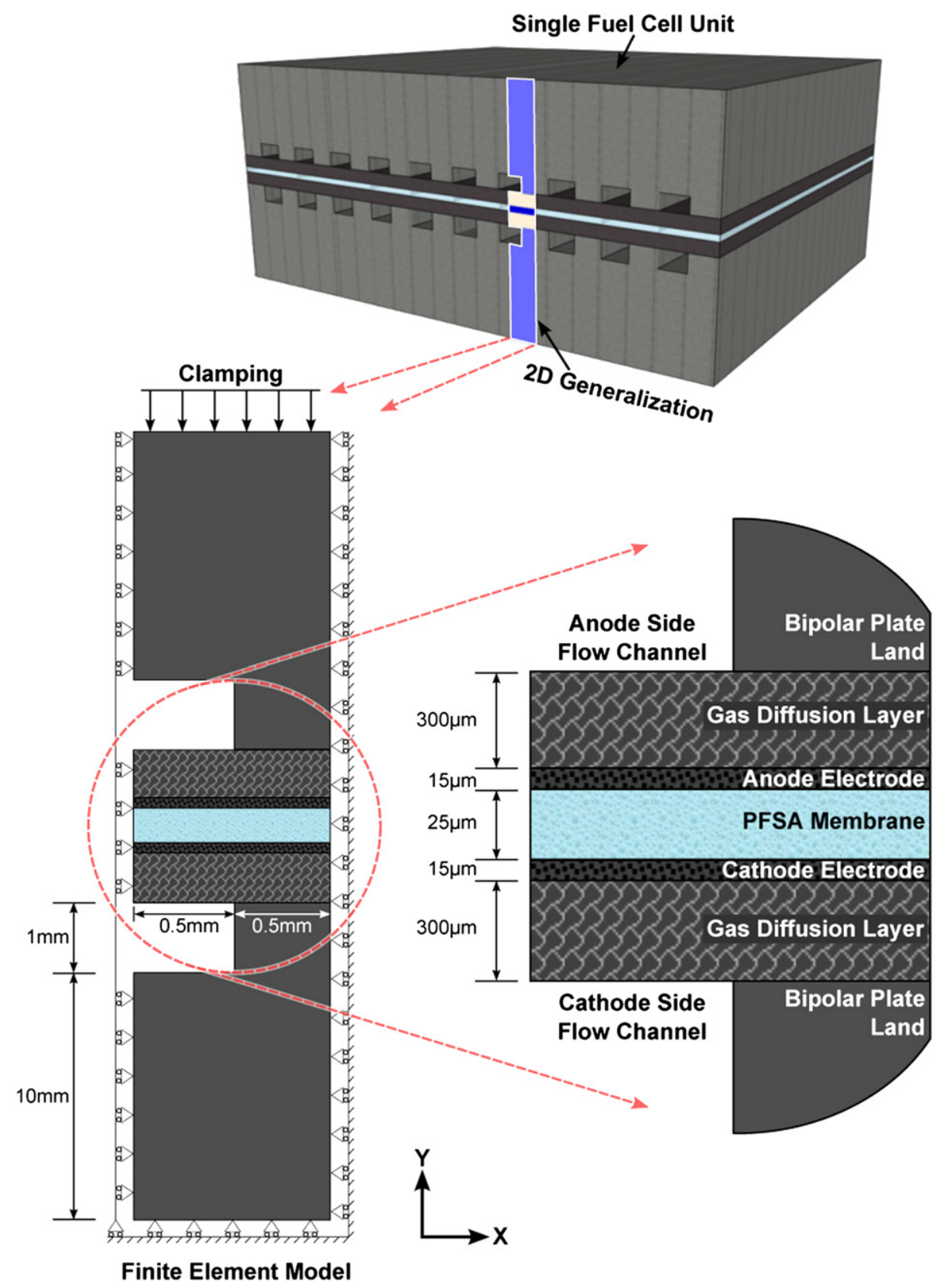

Fig. 5. Schematic of the $2 \mathrm{D}$ generalization of fuel cell unit (not to scale).

\section{Results and discussion}

In our previous work $[6,20,29]$ we have shown that the in-plane stress is the dominant stress in the membrane during fuel cell operation. Consequently, we will focus on that component only. The in-plane stress varies both as a function of time and location. The snapshots displaying the spatial variation of the in-plane stresses in the membrane during the fuel cell simulations under standard $\mathrm{RH}$ cycle loading condition (section 4.3) are shown in Fig. 9. The evolution of the in-plane stress in the membrane for an element on the groove side of the fuel cell is presented in Fig. 10. The particular 'observation point' as chosen in Fig. 10 is a representative element selected to show the general stress evolution behavior. The in-plane stresses caused by the initial clamping pressure of $1 \mathrm{MPa}$, applied at the top of bipolar plate are small in magnitude (Fig. 9A). A parametric study was conducted to investigate the effect of clamping pressure (not shown for brevity). The increased pressure up to 3 MPa results in a minor increase $(<5 \%)$ in the compressive stresses after clamping and hydration and therefore, a similar decrease was found in the residual tensile stress after dehydration.

When the system is subjected to hydration, the membrane takes on water and attempts to swell (from A-B in Fig. 10). Due to the mechanical constraints, the membrane is mostly prevented from deforming in the in-plane direction, resulting in relatively large compressive stresses, on the order of 9-10 MPa (Fig. 9B). During hold at high humidity (10s duration from point $B$ to $C$ in Fig. 10), these compressive, in-plane stresses begin to relax. The redistributed stress profile is shown in Fig. $9 \mathrm{C}$ and it is clear that the overall level of compressive stress is reduced, along with a significant redistribution of the stresses. After hold at high humidity, the system is flushed with dry nitrogen ( $C-D$ in Fig. 10) resulting in a decrease in water content and a decrease in compressive stresses. 


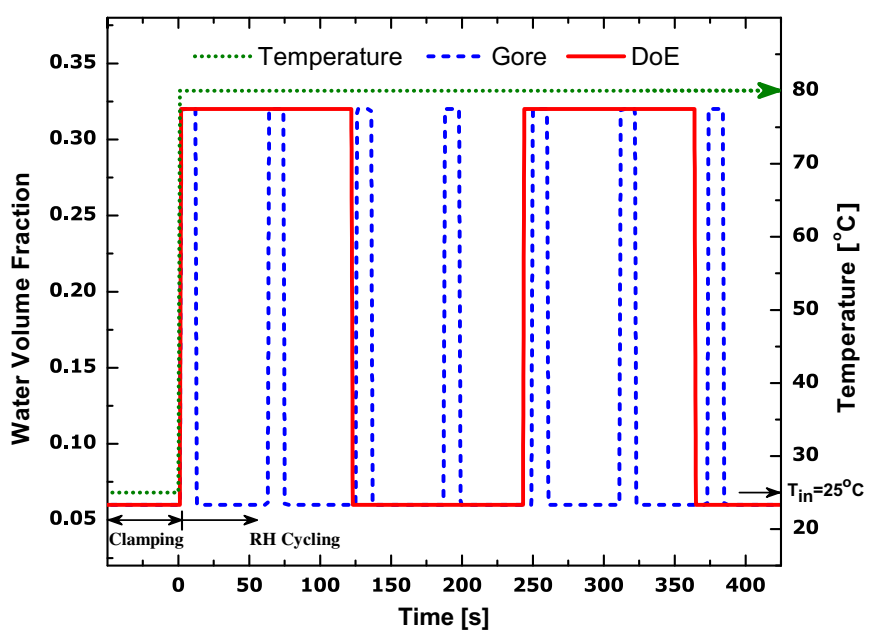

Fig. 6. DoE and GORE RH Cycling Test profile.

This decrease eventually leads to residual tensile in-plane stresses, on the order of 7-8 MPa, as shown in Fig. 9D. During the holding at dry conditions (50s), the membrane in-plane tensile stresses relax considerably (D-E in Fig. 10) and are finally redistributed as shown in Fig. 9E. The figures show that residual stresses under the groove are higher than those under the land. This confirms the trend from our previous work with time-independent properties [6,9,20,29]. However, the time-dependent properties implemented here, result in larger peak for the in-plane stresses after hydration and dehydration compared to the time-independent predictions. During the hold phases, these peak stresses relax to levels below those seen in time-independent simulations.

The hold time at constant hydration and dehydration is longer in the DoE RH cycle than the Gore $\mathrm{RH}$ cycle, allowing for more relaxation (Fig. 10). This results in larger residual tensile stresses after dehydration at the end of the cycle. However, the Gore RH cycling test involves a higher frequency of loading, which produces more reversals of the stresses for a given period of testing. Therefore, without more information on the fatigue resistance of the membranes, it is not possible to determine from these simulations which test cycle will cause earlier failure in the membrane.

The typical strain evolution in the membrane during Gore $\mathrm{RH}$ cycling, for a representative element on the groove side is shown in Fig. 11. The plastic strain magnitude, $\bar{\varepsilon}^{P}=\geq \sqrt{2 / 3 \varepsilon^{\mathrm{pl}}: \varepsilon^{\mathrm{pl}}}$ (is about 0.15 , and therefore, can be instrumental in eventual failure of the membrane.

The transition time (that is, the time assumed for the input $\mathrm{RH}$ load to change linearly from dry to saturated conditions in the standardized RH cycles) is not clearly defined by the testing protocol and may vary for different regions of the fuel cell stack. Therefore, we will study the effect of this transition by varying this time and observing the resulting in-plane stress evolution. The peak in-plane compressive and tensile stresses (corresponding to points B and D in Fig. 10, respectively) for the cycle simulations conducted using selected transition times are shown in Fig. 12. The results indicate that longer transition times result in reductions of both the peak compressive stresses after hydration and peak tensile stresses after dehydration.

In the standard RH cycle protocols, the humidified air is fed simultaneously into both the anode and the cathode side of the fuel cell. However, during real fuel cell operation, the anode side is often less hydrated due to the production of water at the cathode and the electro-osmotic drag, creating a water content gradient [30]. To investigate the effect of loading with gradient water content, we

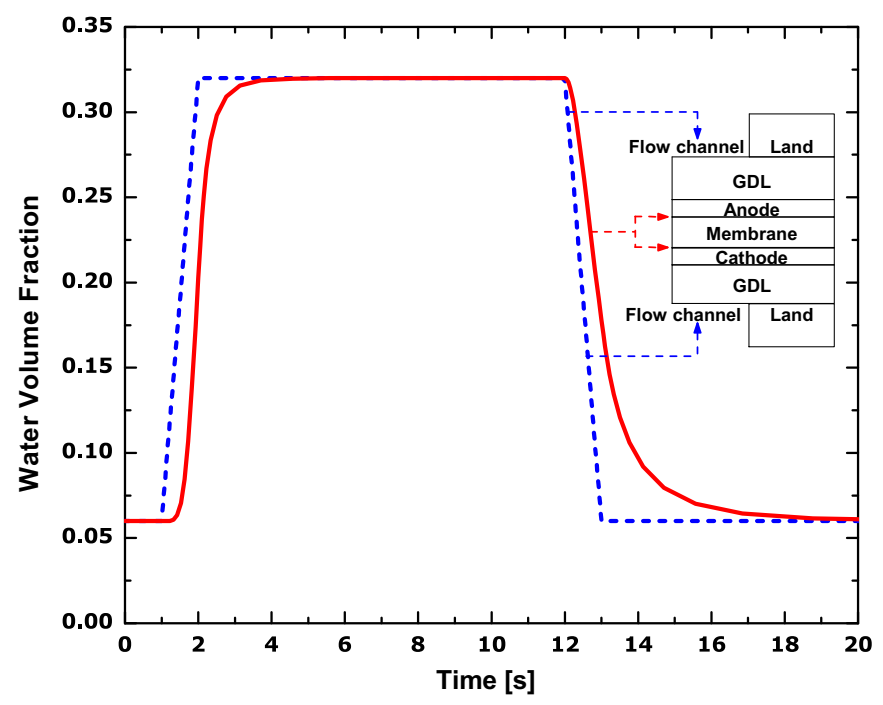

Fig. 7. Water volume fraction variation as seen at membrane-electrode interface compared to input at flow channels indicating swelling time-lag.
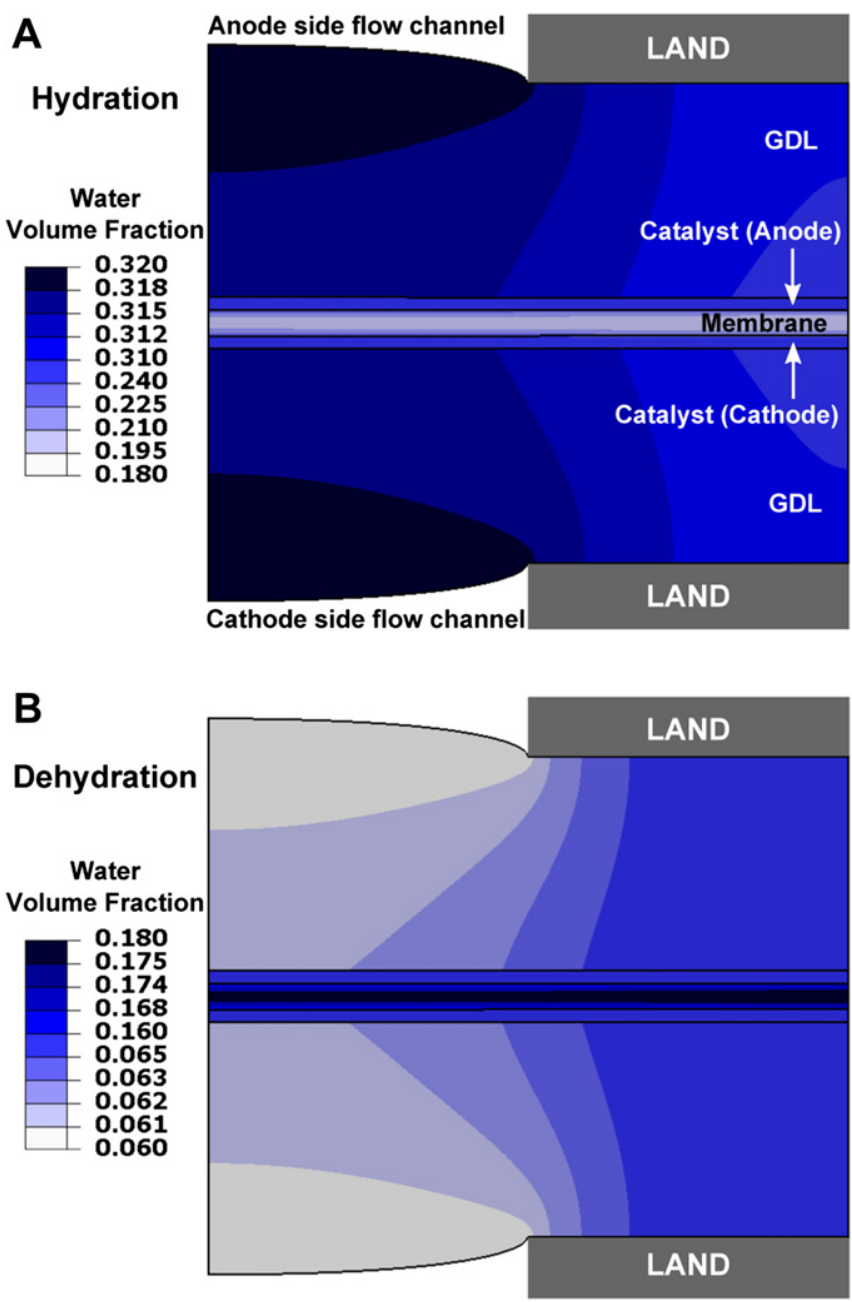

Fig. 8. FE results showing water content in the MEA at the end of $[A]$ hydration and $[B]$ dehydration step of the RH cycle. 
A In-plane stress after clamping

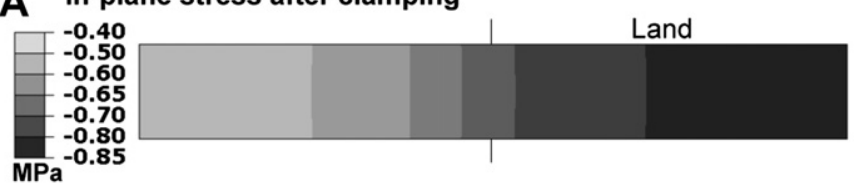

B Maximum in-plane compressive stress after hydration

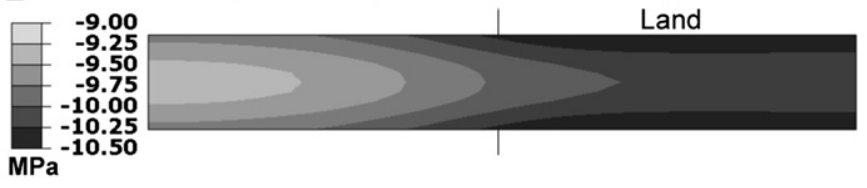

C In-plane stress at the end of hold at high humidity

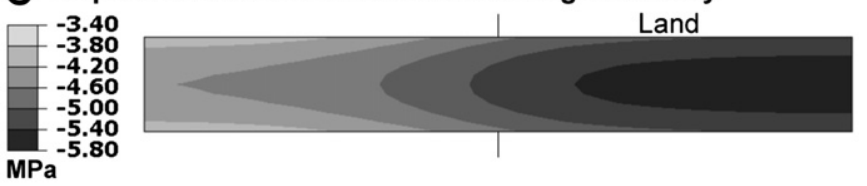

D Maximum in-plane tensile stress after dehydration

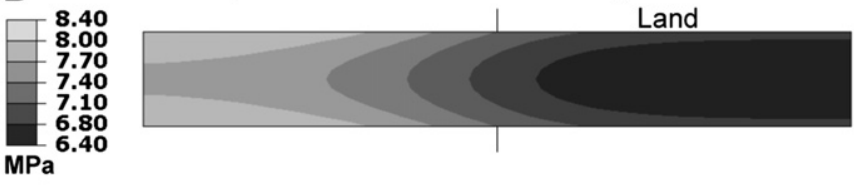

E In-plane stress at the end of hold at dry conditions

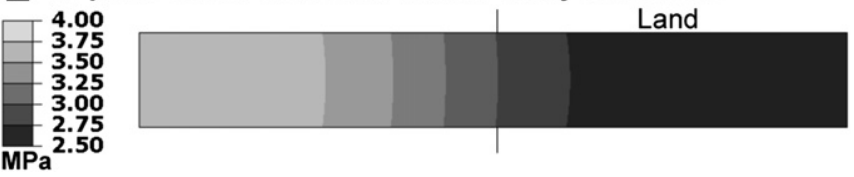

Fig. 9. Contours of the in-plane stress in the membrane during Gore RH cycling (first cycle); $[\mathrm{A}-\mathrm{E}]$ refer to time instants as in Fig. 10.

simulated the case where the cathode side of the membrane is continually subjected to saturated air, while the air at the anode side is cycled according to the Gore RH cycle at a temperature of $80^{\circ} \mathrm{C}$. The contours displaying the spatial variation of the in-plane stress through the thickness are given in Fig. 13. Asymmetric

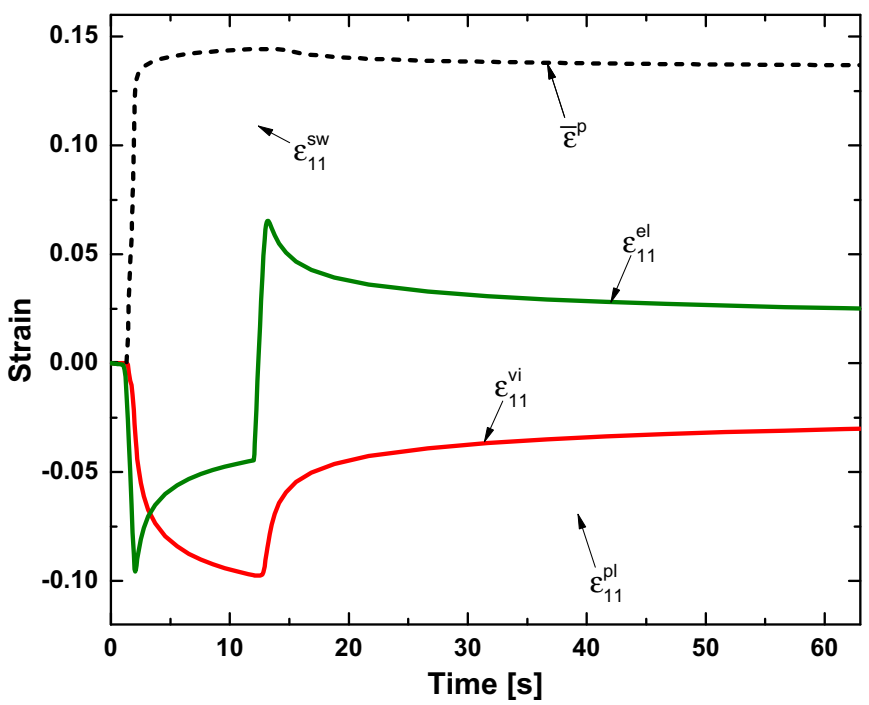

Fig. 11. Typical strain evolution during Gore $\mathrm{RH}$ cycling for an element in the membrane on the groove side. In-plane swelling, elastic, viscous and plastic strain is shown along with total plastic strain magnitude.

distribution of in-plane stress due to non-uniform water content is observed (Fig. 13B, C). After dehydration, a mixed state of stress is observed with the portion of the membrane under the land in compression and the portion under the groove experiencing tension (Fig. 13C).

To further explore this phenomenon, the water content variation, in-plane strain and resulting in-plane stress evolution for two elements under the groove, one on the anode and one on the cathode side of membrane are shown in Fig. 14. It is evident that due to the continual hydration at the cathode, the membrane experiences a smaller differential of water content and less swelling-shrinkage strain, leading to lower overall stress.

As the humidified and dry air are alternatively fed into the channels, the sorption process limits the rate of change in the water content in the GDL, catalyst and membrane. In the present work, the sorption phenomenon is modeled using a diffusion coefficient for the membrane as an empirically derived temperature and water

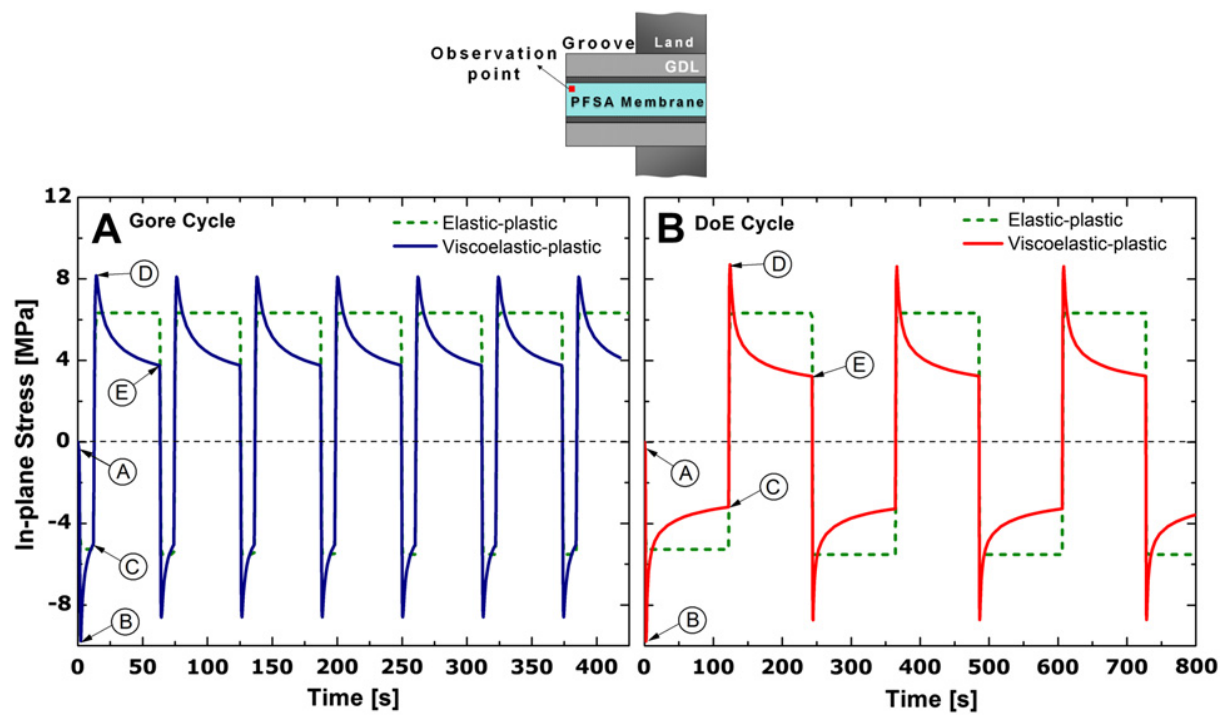

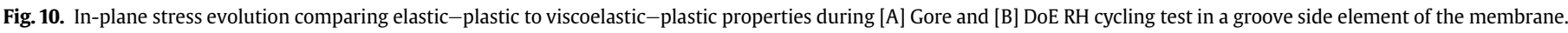
The markers [A-E] correspond to the stress contours shown in Fig. 9. 


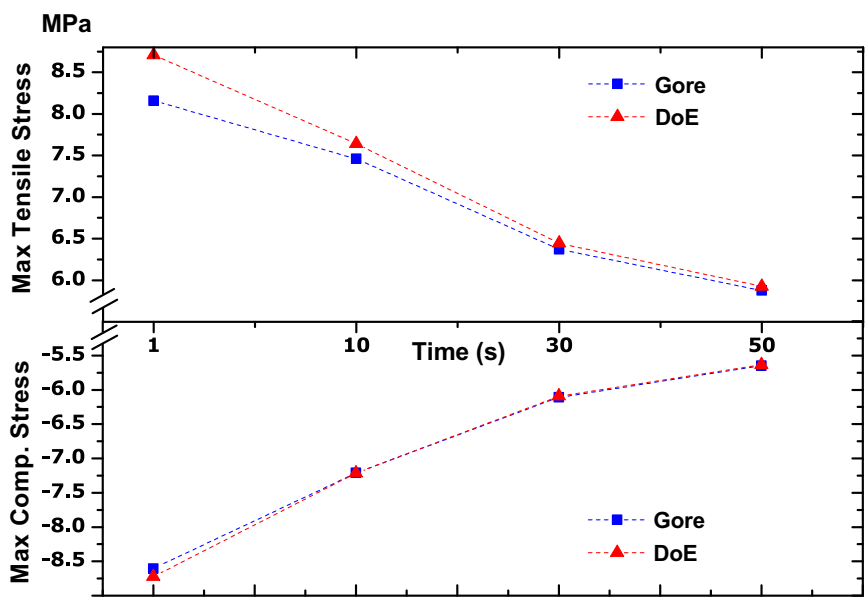

Fig. 12. Effect of hydration/dehydration time on the in-plane compressive and tensile stresses in the membrane for Gore and DoE RH cycling.

content dependent function taken from the work of Weber and Newman [31]. This coefficient affects the dynamic water uptake for the membrane that in turn affects the stress levels. In order to investigate this effect, we ran the simulation with different fractional values of this coefficient [31]. Since the original coefficient values from the literature [31] give relatively fast water uptake, smaller (slower) coefficient values were chosen for the parametric analysis. The resulting water profile variation is shown in Fig. 15A and the in-plane stress evolution in Fig. 15B. The results indicate

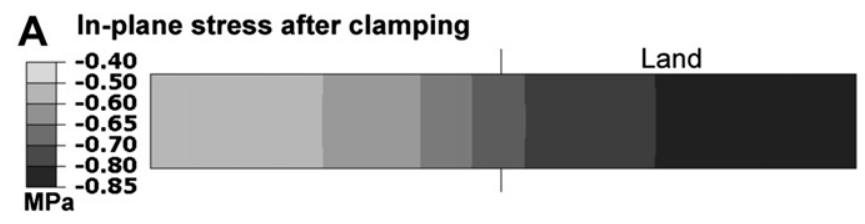

B Maximum in-plane compressive stress after hydration

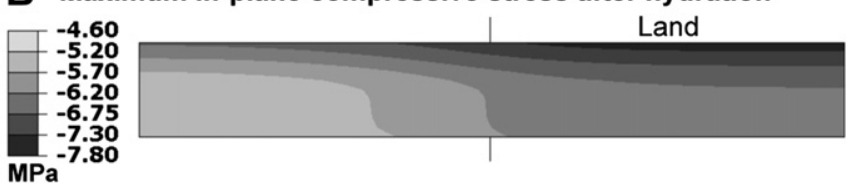

C In-plane stress at the end of hold at high humidity

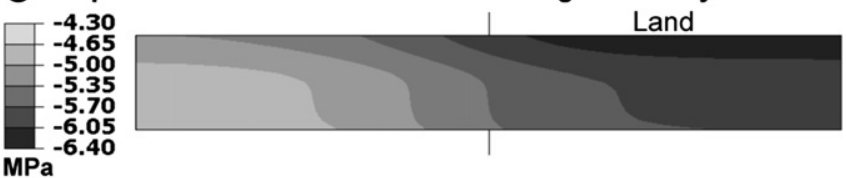

D Maximum in-plane tensile stress after dehydration

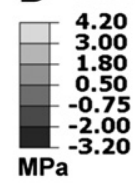

Land

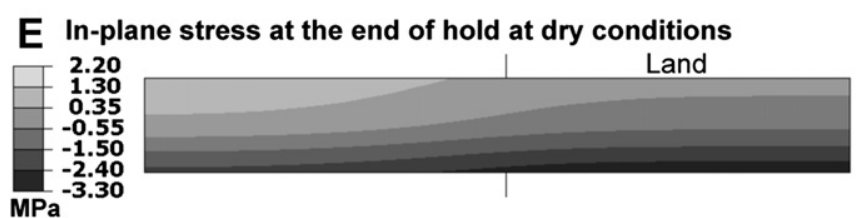

Fig. 13. In-plane stress contours in the membrane under non-uniform (gradient) loading. $[\mathrm{A}-\mathrm{E}]$ refer to time instants in Fig. 14

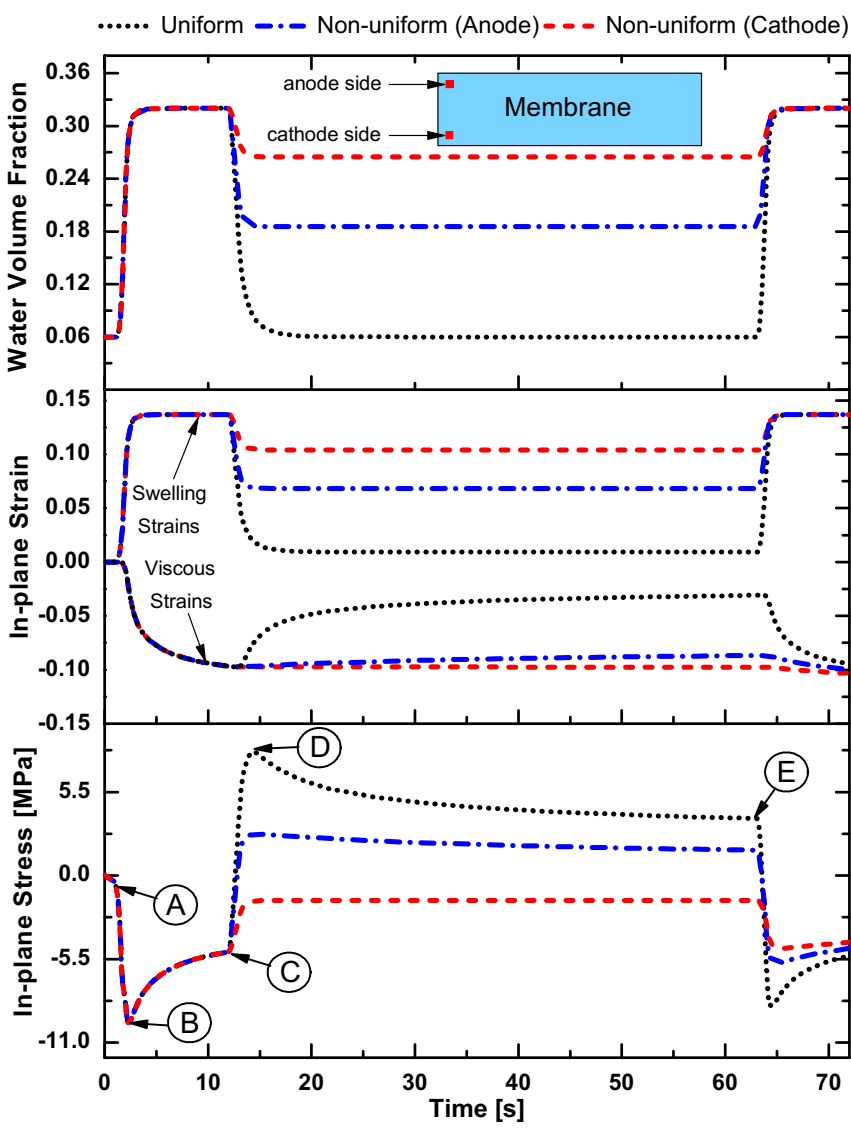

Fig. 14. Water volume fraction, in-plane strain and in-plane stress variation for an element under the groove on the anode side and one on the cathode side of the PFSA membrane for the first cycle under non-uniform (gradient) loading the markers [A-E] correspond to the stress contours shown in Fig. 13.
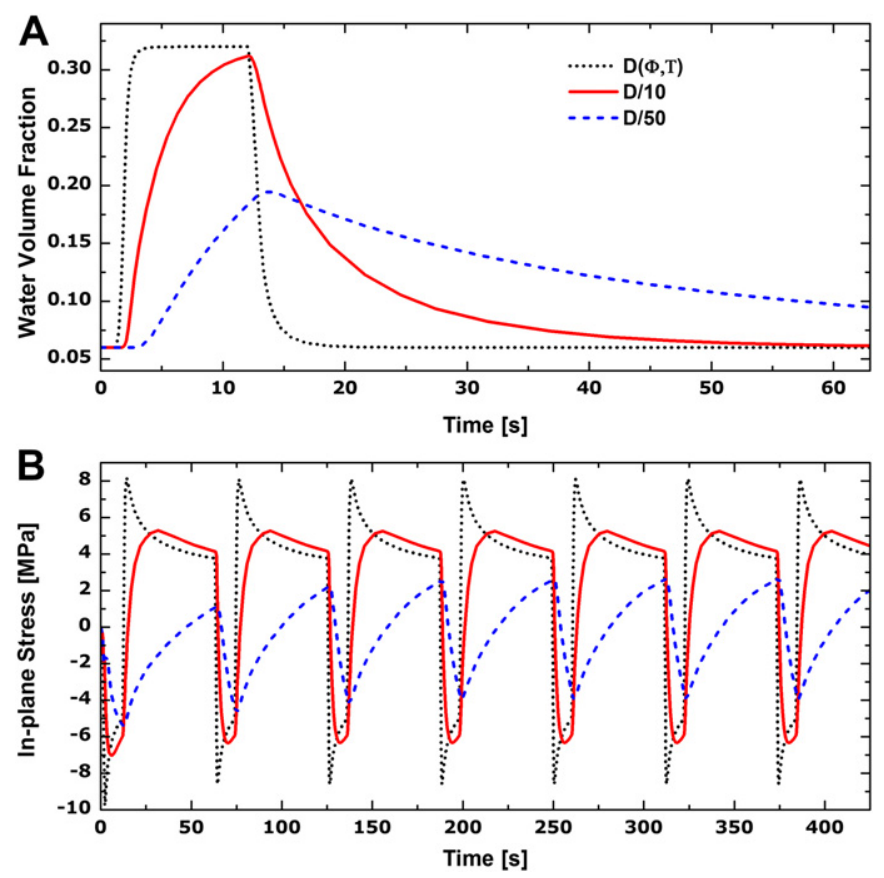

Fig. 15. For three values of sorption coefficient $D(\Phi, T)$ obtained from Weber et al. [31], [A] Water volume fraction variation in the membrane during RH cycling; [B] In-plane stress evolution. 
that with a decreasing value of the coefficient, $\mathrm{D}$, the membrane never gets fully saturated (corresponding to water volume fraction, $\Phi=0.32$ ) during the hydration phase of the cycle and therefore, the stress levels are significantly reduced. In addition, for the lower sorption rate $\mathrm{D} / 50$, the membrane does not reach the dry state $(\Phi$ $=0.06$ ) during the dehydration phase, further reducing the stress levels.

\section{Concluding remarks}

In this work, a two-layer viscoelastic-plastic constitutive model $[21,22]$ was adapted to characterize the time-dependent and ratedependent mechanical response of PFSA membrane under various environmental conditions and load rates spanning a range of fuel cell operation conditions. We modified the standard constitutive model $[21,22]$ by adding strain-rate dependence and determined the specific time-temperature-humidity dependent parameters from our tensile and stress-relaxation experimental data [11] for Nafion ${ }^{\circledR} 211$ membrane. The simulations in section 2 show that the resulting model captures the material response well over the range of temperature, humidity and load rates studied.

The constitutive model was incorporated into a finite element analysis to study the stresses developed in a PFSA membrane, including time-dependent effects, during accelerated mechanical testing. The analysis was conducted as a coupled sorptiondisplacement problem [20] enabling us to model the water content profile and mechanical stresses simultaneously.

The results of the simulations show that (i) the time-dependent models predict larger peak compressive and residual tensile stresses in the membrane as compared to earlier predictions using time-independent properties; (ii) slower feed rates for the humidified air reduce the overall in-plane stresses; (iii) slower sorption rates decrease the swelling strain considerably and hence lower the stresses; (iv) residual in-plane tensile stresses developed in the DoE RH cycles are higher than for the Gore RH cycle, owing to the longer relaxation at constant strains in the former; (v) Uniform moisture feed on both sides of the membrane produces higher stresses as compared to non-uniform loading.

In conclusion, these results suggest that the mechanical degradation and hence the membrane lifetime may be influenced by the inherent time rates of humidity variation during real fuel cell operation. The sites of the largest stress magnitude and cyclic reversals may act as potential damage initiation points and trigger ultimate failure of the membrane. This study adds to the understanding of the mechanical aspects of durability of PEM fuel cells. The numerical model along with carefully determined material properties helps ascertain severe loading cases for the hygrothermal cycling in a fuel cell.

\section{Acknowledgments}

This research has been supported by DOE grant DE-FC36086018052 through a subcontract from W. L. Gore \& Associates, Inc.

\section{Appendix A. Tensile simulation}

In this section, derivation of the stresses in individual layers of the two-layer viscoelastic-plastic model $[21,22]$ for tensile loading is explained. In order to visualize the individual effects of the parameters in the two-layer model (see Fig. 1), we investigate the model response during a generic tensile test simulation, using generic properties.

In a displacement-controlled tensile test, the strain rate, $\dot{\varepsilon}$, is nearly constant. The strain evolution for each of the individual parameters of the constitutive model is shown in Fig. A1-A. In the elastic-plastic layer, the strain, $\varepsilon_{\mathrm{el}}^{\mathrm{EP}}$, in the elastic element, $K_{\mathrm{P}}$, changes linearly until the elastic limit is reached. Thereafter, the elastic strain increases monotonically at a reduced rate. The plastic strain, $\varepsilon_{\mathrm{pl}}^{\mathrm{EP}}$, appears after the proportional limit is reached and increases linearly beyond this limit. Similarly, in the elastic-viscous layer, the strain, $\varepsilon_{\mathrm{el}}^{\mathrm{EV}}$, in the elastic element, $K_{\mathrm{V}}$, initially increases linearly until the time-dependent dashpot is activated. Once the dashpot is activated, there is no further increase in the strain for the elastic element, while the viscous strain, $\varepsilon_{\mathrm{vi}}^{\mathrm{EV}}$, increases linearly. For one-dimensional loading, the total stress is given by the sum of stresses in the two layers (Fig. A1-B),

$\sigma=\sigma^{\mathrm{EP}}+\sigma^{\mathrm{EV}}$

The stress $\sigma^{\mathrm{EP}}$ in the elastic-plastic layer is given by

$\sigma^{\mathrm{EP}}=\left\{\begin{array}{cl}K_{\mathrm{P}} \varepsilon & ; \sigma^{\mathrm{EP}} \leq \sigma_{\mathrm{y}} \\ \xi_{\mathrm{y}}+H\left(\varepsilon-\varepsilon_{\mathrm{c}}\right) & ; \sigma^{\mathrm{EP}}>\sigma_{\mathrm{y}}\end{array}\right.$

where $\varepsilon_{\mathrm{c}}=\sigma_{\mathrm{y}} / K_{\mathrm{P}}, K_{\mathrm{P}}$ is the elastic stiffness and $H$ is the post-yield slope of the true stress vs. true strain curve for the elastic-plastic layer. $H$ can generally be any function of strain in addition to having hygral and thermal dependence. Using the information from our experiments, the form of $H$ used in this work is such that

$H=H(\varepsilon, \lambda, \theta)=H(\lambda, \theta) ; \varepsilon<0.3$.

The stress in the elastic-viscous layer results in a first-order inhomogeneous, non-linear differential equation. Again, assuming one-dimensional loading, the individual elastic and viscous stresses in the elastic-viscous layer are equal to the total stress

$\sigma^{\mathrm{EV}}=\sigma_{\mathrm{el}}^{\mathrm{EV}}=\sigma_{\mathrm{vi}}^{\mathrm{EV}}$.

The strain in the elastic-viscous layer, given by Eq. (14) when written in one-dimensional form $(i, j=1)$ gives the following expression

$\varepsilon^{\mathrm{EV}}=\varepsilon_{\mathrm{el}}^{\mathrm{EV}}+\varepsilon_{\mathrm{vi}}^{\mathrm{EV}}$,

where the elastic strain is related to the stiffness, $K_{\mathrm{V}}$ and is given by

$\varepsilon_{\mathrm{el}}^{\mathrm{EV}}=\frac{\sigma_{\mathrm{el}}^{\mathrm{EV}}}{K_{\mathrm{V}}}$

Differentiating Eq. A-5 with respect to time, $t$, and substituting the viscous strain $\varepsilon_{\mathrm{vi}}^{\mathrm{EV}}$ from Eq. (16) and elastic strain $\varepsilon_{\mathrm{el}}^{\mathrm{EV}}$ from Eq. (A-6), we get a relationship between the strain rate, stress and stress rate,

$\dot{\varepsilon}^{\mathrm{EV}}=\frac{\dot{\sigma}_{\mathrm{el}}^{\mathrm{EV}}}{K_{\mathrm{V}}}+A\left(\sigma_{\mathrm{vi}}^{\mathrm{EV}}\right)^{n}$

where a "dot" above the quantity represents its derivative with respect to time. Rearranging Eq. (A-7), and using Eq. (A-4) we can write the resulting constitutive equation for the elastic-viscous layer as

$\dot{\sigma}^{\mathrm{EV}}+A K_{\mathrm{V}}\left(\sigma^{\mathrm{EV}}\right)^{n}-K_{\mathrm{V}} \dot{\varepsilon}^{\mathrm{EV}}=0$,

where $\dot{\varepsilon}^{\mathrm{EV}}=\dot{\varepsilon}^{\mathrm{M}}=\dot{\varepsilon}$ is the total strain rate. The solution to this equation is found numerically using illustrative properties and the resulting stress (Fig. A1-B) shows an increase with an increase in $K_{\mathrm{V}}$ to a constant maximum value of

$\sigma^{\mathrm{EV}}=\geq \frac{\dot{\varepsilon}}{A}^{1 / n}$ 
Eq. (A-9), when combined with Eq. (A-2) gives the total stress for the model under constant strain rate loading (assuming inelastic deformation) as

$\sigma=\sigma_{\mathrm{y}}+H\left(\underline{\underline{q}}-\varepsilon_{\mathrm{c}}\right)+\geq \frac{\dot{\varepsilon}}{A}^{1 / n}$

\section{Appendix B. Relaxation simulation}

In a typical stress-relaxation test, the specimen is quickly loaded to a desired strain. The strain is then held constant and the reduction in stress is measured as a function of time. During a stress-relaxation simulation using generic properties, the strain in the individual components of the constitutive model varies as shown in Fig. B1-A. The stress in the model at the end of the initial loading (tension) can be determined by Eq. (A-10), which is also the initial stress for the relaxation phase. During the relaxation period, the stress in the elastic-plastic layer, $\sigma^{\mathrm{EP}}$, is unchanged, while the stress in the elastic-viscous layer, $\sigma^{\mathrm{EV}}$, decreases due to dissipation in the viscous element, as illustrated in Fig. B1-B. The stress in the elastic-plastic layer is still given by Eq. (A-2), but during relaxation, the stress in the elastic-viscous layer evolves as the strain components are redistributed. Therefore, to determine total stress for the model, the stress in the elastic-viscous layer alone needs to be evaluated.

During the stress-relaxation period, the strain, $\varepsilon_{\mathrm{el}}^{\mathrm{EV}}$, in the elastic element, $K_{\mathrm{V}}$, of the elastic-viscous layer decreases as the dashpot lengthens, such that the total strain in the layer remains constant (Fig. B1-A),

$\varepsilon_{\mathrm{el}}^{\mathrm{EV}}+\varepsilon_{\mathrm{vi}}^{\mathrm{EV}}=\varepsilon$.

Thus, upon differentiating and rearranging Eq. (B-1), the following relationship between the strain rates is obtained,

$\dot{\varepsilon}_{\mathrm{vi}}^{\mathrm{EV}}=-\dot{\varepsilon}_{\mathrm{el}}^{\mathrm{EV}}$.

The viscous strain rate $\left(\dot{\varepsilon}_{\mathrm{vi}}^{\mathrm{EV}}\right)$ is governed by Eq. (16), in which it can be replaced by the corresponding negative elastic strain rate using Eq. (B-2), giving

$-\dot{\varepsilon}_{\mathrm{el}}^{\mathrm{EV}}=A\left(\sigma^{\mathrm{EV}}\right)^{n}$.

Eq. (B-3) can be simplified using Eqs. (A-4) and (A-6) to

$\dot{\sigma}^{\mathrm{EV}}+A K_{\mathrm{V}}\left(\sigma^{\mathrm{EV}}\right)^{n}=0$.

Eq. (B-4) is a first-order homogeneous non-linear equation in $\sigma^{\mathrm{EV}}$ with the solution

$\sigma^{\mathrm{EV}}=\left[\begin{array}{ll}\dot{\varepsilon}^{\frac{(1-n) \geq}{n}}+\geq n-1 & A K_{\mathrm{V}} t\end{array}\right]^{\frac{1}{(1-n) \geq}}$.

Therefore the total stress during stress-relaxation is given by the sum of Eqs. (A-2) and (B-5) as

$\sigma=\sigma_{\mathrm{y}}+H\left(\varepsilon-\varepsilon_{\mathrm{c}}\right)+\left[\left(\dot{\varepsilon}_{\frac{\dot{\varepsilon}}{A}^{\frac{(1-n) \geq}{n}}+n-1}+A K_{\mathrm{v}} t\right]^{\frac{1}{(1-n)}}\right.$.

The maximum value of the total stress $\sigma$ at the end of a tensile pull with strain $\varepsilon$ as given by Eq. (A-10) can be recovered from the Eq. (B-6) by substituting $t=0$. During stress-relaxation, which occurs for $t>0$, the stress in the elasticviscous layer, $\sigma^{\mathrm{EV}}$, given by Eq. (B-5) decreases as shown in Fig. B1-B, and as a result the total stress, $\sigma$ given by Eq. (B-6) relaxes to an equilibrium value equal to the stress in elastic-plastic layer given by Eq. (A-2).

The stress-relaxation data obtained at each environmental condition is fit to the Eq. (B-6) and the elastic-viscous parameters $A$, $n$ and $K_{\mathrm{v}}$ are determined. The time-independent portion of the Eq. (B-6) which is also given by Eq. (A-2), is then used to construct a 'quasi-static' curve from which the elastic-plastic parameters $\sigma_{\mathrm{y}}$, $H$ and $K_{\mathrm{p}}$ are determined.
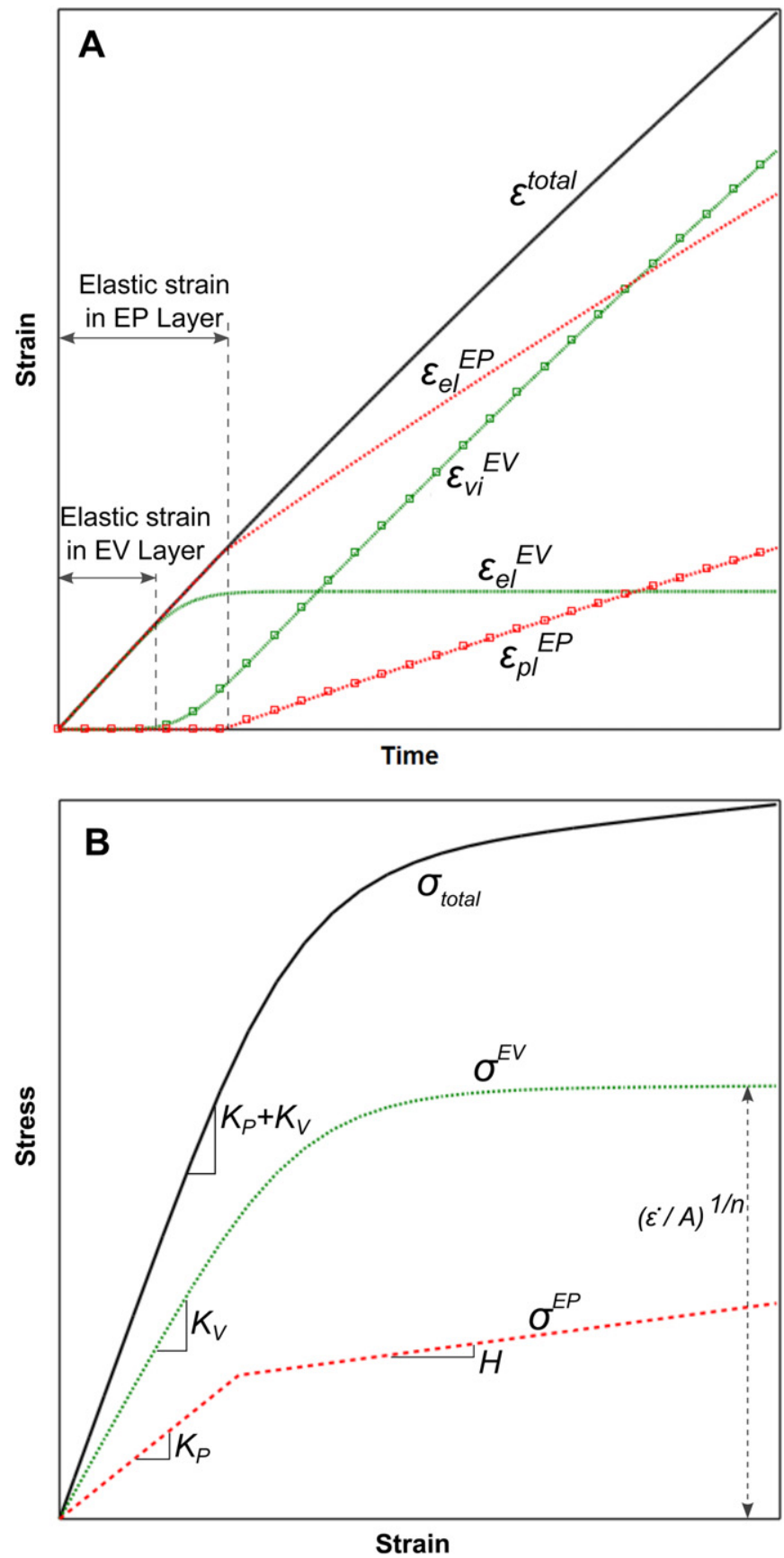

Fig. A1. [A] Typical strain evolution and [B] typical stress evolution during uniaxial displacement-controlled tensile test simulation. 


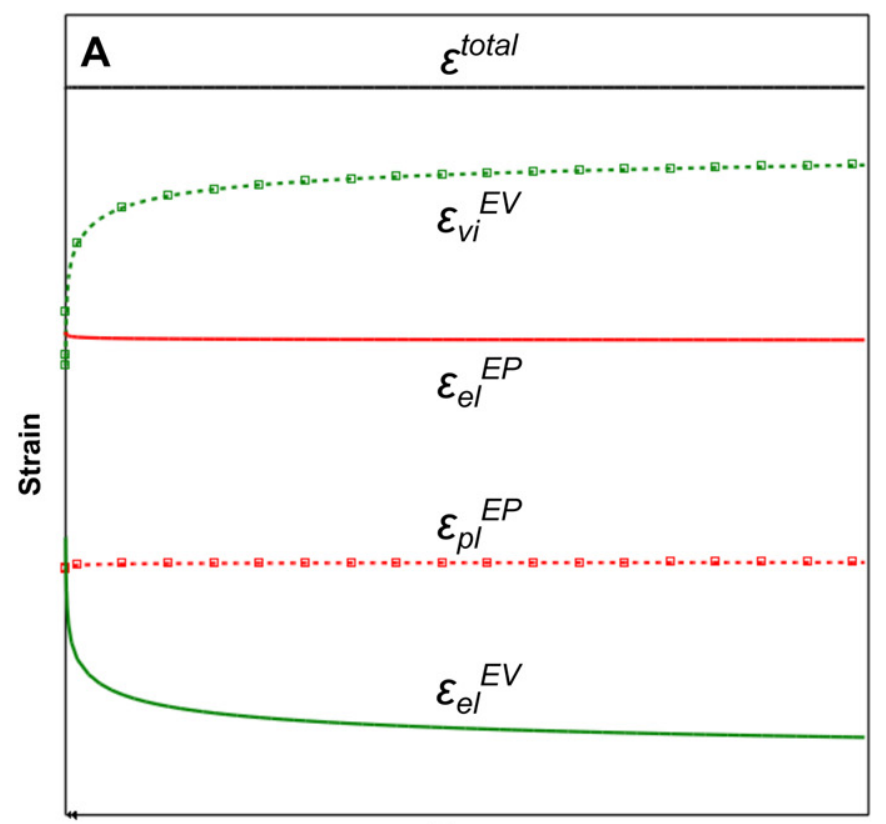

\section{Time}

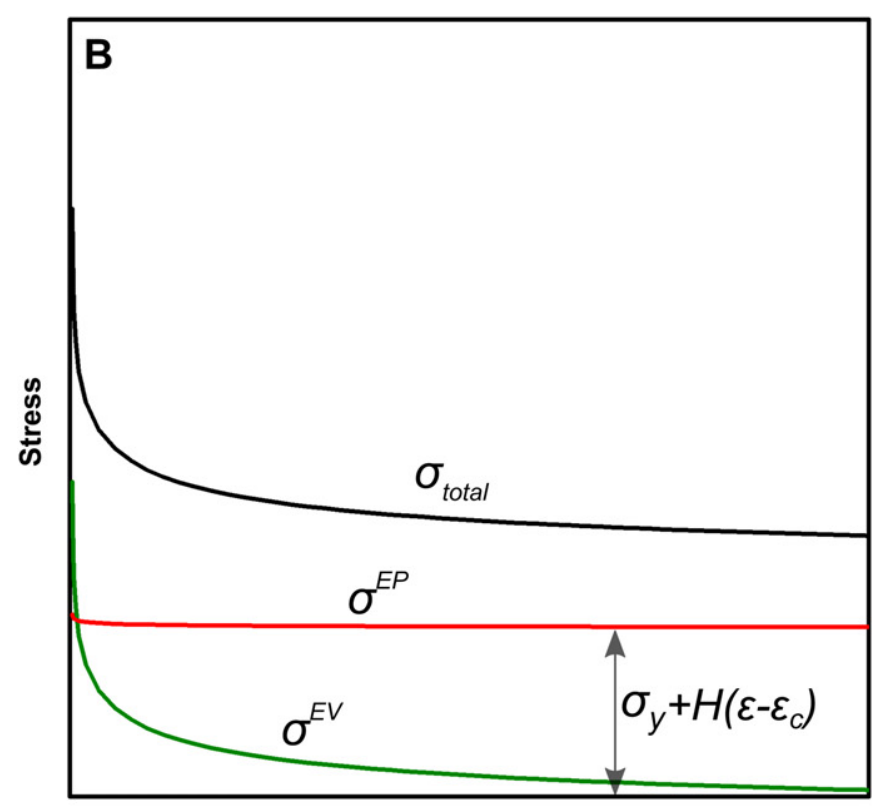

Time

Fig. B1. $[\mathrm{A}]$ Typical strain evolution and $[\mathrm{B}]$ typical stress evolution during uniaxial stress-relaxation test simulation.

\section{References}

[1] R. Borup, J. Meyers, B. Pivovar, Y.S. Kim, R. Mukundan, N. Garland, D. Myers, M. Wilson, F. Garzon, D. Wood, P. Zelenay, K. More, K. Stroh, T. Zawodzinski, J. Boncella, J.E. McGrath, M. Inaba, K. Miyatake, M. Hori, K. Ota, Z. Ogumi, S. Miyata, A. Nishikata, Z. Siroma, Y. Uchimoto, K. Yasuda, K.I. Kimijima, N. Iwashita, Chemical Reviews 107 (2007) 3904-3951.

[2] U.S. DOE.http://www1.eere.energy.gov/hydrogenandfuelcells (2007).

[3] J.R. Yu, B.L. Yi, D.M. Xing, F.Q. Liu, Z.G. Shao, Y.Z. Fu, Physical Chemistry Chemical Physics 5 (2003) 611-615.

[4] C.S. Gittleman, F.D. Coms, Y.-H. Lai, Membrane durability: physical and chemical degradation, in: M. Mench, E.C. Kumbur, T.N. Veziroglu (Eds.), Modern Topics in Polymer Electrolyte Fuel Cell Degradation, Elsevier, 2011, pp. 15-88.

[5] N.L. Garland, T.G. Benjamin, J.P. Kopasz, ECS Transactions 11 (2007) 923-931.

[6] A. Kusoglu, A.M. Karlsson, M.H. Santare, S. Cleghorn, W.B. Johnson, Journal of Power Sources 161 (2006) 987-996.

[7] A. Kusoglu, A.M. Karlsson, M.H. Santare, S. Cleghorn, W.B. Johnson, Journal of Power Sources 170 (2007) 345-358.

[8] Y.L. Tang, A. Kusoglu, A.M. Karlsson, M.H. Santare, S. Cleghorn, W.B. Johnson, Journal of Power Sources 175 (2008) 817-825.

[9] Y.L. Tang, M.H. Santare, A.M. Karlsson, S. Cleghorn, W.B. Johnson, Journal of Fuel Cell Science and Technology 3 (2006) 119-124.

[10] X.Z. Yuan, H. Li, S.S. Zhang, J. Martin, H.J. Wang, Journal of Power Sources 196 (2011) 9107-9116.

[11] Z. Lu, M.H. Santare, A.M. Karlsson, P. Walsh, C. Busby, Journal of Power Sources, Available online 3 May 2012, ISSN 0378-7753, 10.1016/j.jpowsour.2012.04.094.

[12] R. Solasi, Y. Zou, X.Y. Huang, K. Reifsnider, Mechanics of Time-Dependent Materials 12 (2008) 15-30.

[13] M.N. Silberstein, M.C. Boyce, Journal of Power Sources 195 (2010) 5692-5706.

[14] W. Yoon, X.Y. Huang, Journal of Power Sources 196 (2011) 3933-3941.

[15] K. Patankar, D. Dillard, S. Case, M. Ellis, Y.-H. Lai, M. Budinski, C. Gittleman, Mechanics of Time-Dependent Materials 12 (2008) 221-236.

[16] L. Yan, T.A. Gray, K.A. Patankar, S.W. Case, M.W. Ellis, R.B. Moore, D.A. Dillard, Y.-H. Lai, Y. Li, C.S. Gittleman, in: T. Proulx (Ed.), The Nonlinear Viscoelastic Properties of PFSA Membranes in Water-immersed and Humid Air Conditions Experimental Mechanics on Emerging Energy Systems and Materials, vol. 5, Springer, New York, 2011, pp. 163-174.

17] Y.H. Lai, C.K. Mittelsteadt, C.S. Gittleman, D.A. Dillard, Journal of Fuel Cell Science and Technology 6 (2009) 13.

[18] M.N. Silberstein, M.C. Boyce, Journal of Power Sources 196 (2011) 3452-3460.

[19] Y.Q. Li, D.A. Dillard, Y.H. Lai, S.W. Case, M.W. Ellis, M.K. Budinski, C.S. Gittleman, Journal of the Electrochemical Society 159 (2012) B173-B184.

[20] A. Kusoglu, M.H. Santare, A.M. Karlsson, S. Cleghorn, W.B. Johnson, Journal of the Electrochemical Society 157 (2010) B705-B713.

[21] J. Kichenin, K.D. Van, K. Boytard, Journal of Materials Science 31 (1996) 1653-1661.

[22] ABAQUS, in: ABAQUS Inc, 2009.

[23] R. von Mises, Mathematische-Physikalische Klasse, Göttinger Nachrichten 1 (1913) 582-592.

[24] F.H. Norton, Creep of Steel at Higher Temperatures, McGraw-Hill Book Co, New York, 1929.

[25] R. Solasi, Y. Zou, X. Huang, K. Reifsnider, D. Condit, Journal of Power Sources 167 (2007) 366-377.

[26] Z.W. Lu, C. Kim, A.M. Karlsson, J.C. Cross, M.H. Santare, Journal of Power Sources 196 (2011) 4646-4654.

[27] M.F. Mathias, R. Makharia, H.A. Gasteiger, J.J. Conley, T.J. Fuller, C.S. Gittleman S.S. Kocha, D.P. Miller, C.K. Mittelsteadt, T. Xie, S.G. Yan, P.T. Yu, Interface (2005) 24-35.

[28] W. Liu, S. Cleghorn, ECS Transactions (2006) 263-273.

[29] A. Kusoglu, Y.L. Tang, M.H. Santare, A.M. Karlsson, S. Cleghorn, W.B. Johnson, Journal of Fuel Cell Science and Technology 6 (2009).

[30] T.E. Springer, T.A. Zawodzinski, S. Gottesfeld, Journal of the Electrochemical Society; (United States) 138 (1991) 8 Medium: X; Size: Pages: 2334-2341.

[31] A.Z. Weber, J. Newman, Journal of the Electrochemical Society 151 (2004) A311-A325. 